\title{
The decreased expression of TIPE2 protein in the decidua of patients with missed abortion and possible significance
}

Yingshuo Sun ${ }^{1,2+}$, Xiaoyan Wang ${ }^{2 \dagger}$, Yue Li ${ }^{2}$, Han Sun ${ }^{2,3}$, Lu Wan $^{2}$, Xishuang Wang ${ }^{2}$, Lining Zhang ${ }^{2}$, Zhenghui Fang ${ }^{4}$ and Zengtao Wei $\mathrm{i}^{1,2,4^{*}}$ (i)

\begin{abstract}
Background: Missed abortion is a common occurrence for otherwise healthy women. Immunological factor is one of the most important reasons. Tumor necrosis factor-a-induced protein-8 like-2 (TIPE2) is a novel negative immune regulator related to several human diseases. However, the expression level and clinical significance of TIPE2 in missed abortion remain unclear.

Methods: The expression of TIPE2 mRNA and protein in decidua and chorion from 36 missed abortion patients and 36 healthy controls was detected using quantitative real-time PCR, western blot and immunohistochemistry. In addition, serum TNF- $\mathrm{a}$ and IL-10 levels were measured using flow cytometry. Serum estradiol and progesterone levels were measured by radioimmunoassay test. The correlations of TIPE2 protein levels with TNF-a, IL-10, estradiol and progesterone were further analyzed.

Results: TIPE2 protein levels were significantly lower in decidual tissues of missed abortion patients than those in healthy controls. The patients with missed abortion had significantly higher levels of serum TNF-a, and lower levels of serum IL-10, estradiol and progesterone compared with healthy controls. The TIPE2 protein levels were positively related to serum IL-10 levels.

Conclusion: Our data indicate TIPE2 could play important roles in maintaining the maternal-fetal tolerance and decreased TIPE2 expression in the decidua may be related to the development of missed abortion.
\end{abstract}

Keywords: Missed abortion, TIPE2, Cytokine, Hormone

\section{Background}

TIPE2, a member of the TNFAIP8 family, is a newly identified negative regulator of inflammation and immunity [1-4]. It is also called TNF- $\alpha$-induced protein 8-like 2 (TNFAIP8L2) and highly expressed in murine inflamed tissues $[1,5]$. It has been reported that mouse TIPE2 is preferentially expressed in hematopoietic cells, such as macrophages, B and T lymphocytes [1]. Its deficiency leads to multi-organ inflammation, splenomegaly

\footnotetext{
*Correspondence: weizengtao1970@163.com; weizengtao@sdu.edu.cn ${ }^{\dagger}$ Equal contributors

'Department of Gynecology and Obstetrics, Clinical Medical School, Shandong University, 44\# Wenhua Xi Road, Jinan, Shandong 250012, People's Republic of China

2Department of Immunology, School of Basic Medical Sciences, Shandong University, 44\# Wenhua Xi Road, Jinan, Shandong, People's Republic of China Full list of author information is available at the end of the article
}

and premature death in mice [1]. There are high levels of pro-inflammatory cytokines such as interleukin (IL)-1, IL-6, IL-12 and TNF- $\alpha$ as well as the inhibitory cytokine IL-10 in the serum of TIPE2-knockout mice [1]. However, human TIPE2 is expressed in both tissues of the immune system and non-immune tissues [6-10], including hepatocytes and neurons. Abnormal TIPE2 expression exists in patients with chronic inflammatory diseases and cancers, and correlates with the progression of diseases, which suggests that TIPE2 plays important roles in neoplastic and inflammatory diseases [11-15].

Missed abortion is defined as the arrest of embryonic or fetal development with ultrasound findings of an empty gestational sac or an embryo/fetus without cardiac activity [16]. It is a common occurrence for otherwise healthy women. At present, the multiple 
etiologic factors including genetic and uterine abnormalities, endocrine and immunological dysfunctions, infections, nutritional and environmental factors, psychogenetic factors, and endometriosis, have been identified [17-19]. Among them, an altered immunological environment associated with idiopathic early pregnancy demise should be emphasized [20]. It has been known that the genome of the embryo comes from the mother and the father equally, therefore, the fetus is a kind of semi- allograft for the mother [21, 22]. The regulation of immune system during pregnancy is essential for maintaining the immune tolerance to fetal semi-allograft and preventing the attack of immunologically distinct fetus by maternal immune system [23-26]. The association between missed abortion and inflammation or immunity is widely recognized, however, the expression status and role of human TIPE2 in patients with missed abortion remain unclear.

In the present study, we detected the expression status of TIPE2 in decidua and chorion of missed abortion patients and healthy controls at both mRNA and protein level by quantitative real-time PCR, western blot and immunohistochemistry. In addition, we also investigated Th1-type cytokine TNF-a, Th2-type cytokine IL-10, estradiol and progesterone in the serum of patients with missed abortion and healthy controls, and evaluate the correlations of TIPE2 expression with cytokines, estradiol and progesterone in missed abortion patients. The results demonstrated that missed abortion patients have decreased expression of TIPE2 in decidual tissues. Altered expression of TIPE2 could contribute to the pathophysiology of missed abortion.

\section{Methods}

\section{Human subjects}

Thirty-six patients with missed abortion and 36 healthy controls with normal induced abortions were recruited from Department of Obstetrics and Gynecology in Jinan Central Hospital affiliated Shandong University from January to December, 2015. At first, we excluded pregnancies affected with significant chromosome abnormalities. All of the women examined had no any sign of autoimmune disorders, clinical genital infections or any other systemic disease, and hormone treatment in nearly three months. Gestation time (7-12 weeks) was evaluated based on the last menstrual period, and confirmed by ultrasound examination. All decidual and chorionic tissues were washed in $0.9 \% \mathrm{NaCl}$ as soon as they had been removed from the uterus. Each sample was divided into two parts: one part was fixed overnight in $4 \%$ formaldehyde at room temperature for immunohistochemistry, and the other part was frozen in a $-80{ }^{\circ} \mathrm{C}$ refrigerator until protein and RNA extraction. The serum was collected before the participants were operated. The detailed demographic and clinical data were presented in Table 1 . There are no statistically significant differences in the data, including maternal age, gestation age and gravity between missed abortion patients and healthy controls.

\section{RNA isolation, quantitative real-time PCR (qRT-PCR)}

Total RNAs of decidua and chorion were extracted using a modified TRIzol one-step extraction method (TIANGEN, Beijing, China). The concentration of RNA was determined by ultraviolet absorption spectrometry. The same amount of RNA $(2 \mu \mathrm{g})$ was reversely transcribed to cDNA using the Fast Quant RT Kit (TIANGEN, Beijing, China) according to the manufacture's instruction. cDNA was used as template for the amplification of TIPE2 gene. Real-time PCR was performed using UltraSYBR Mixture and TIPE2 specific primers (CWBIO, Beijing, China) according to the manufacture's protocol in the Bio-Rad CFX96. The sequences of TIPE2 specific primers were as follows: forward 5'-GGAACATCC AAGGCAAGACTG-3' and reverse 5'-AGCACCTCA CTGCTTGTCTCATC-3'. The qRT-PCR reaction was performed according to the following conditions: predenaturation at $95{ }^{\circ} \mathrm{C}$ for $10 \mathrm{~min}$, followed by 39 cycles of amplification at $95{ }^{\circ} \mathrm{C}$ for $15 \mathrm{~s}, 60^{\circ} \mathrm{C}$ for $1 \mathrm{~min}, 65^{\circ} \mathrm{C}$ for $5 \mathrm{~s}$. Each sample was conducted in triplicate. Data were analyzed using the $2-\triangle \Delta C$ t method. TIPE2 data were normalized to the mRNA levels of housekeeping gene GAPDH. The primer sequences for GAPDH were shown as the following: forward 5 '-AACGGATTTGGT CGTATTGGG-3' and reverse $5^{\prime}$-CCTGGAAGATGGTGATGG GAT-3' .

\section{Western blot}

Proteins were extracted from decidua and chorion using a modified TRIzol one-step extraction method. Protein concentration was detected by a BCA protein assay kit (Thermo Scientific, MA, USA). Total proteins were separated by $15 \%$ sodium dodecylsulfate-polyacrylamide gel electrophoresis and transferred to PVDF membranes (Millipore, Billerica, MA, USA). After blocking with $2 \%$ BSA in TBST containing $0.1 \%$ Tween-20 for $1 \mathrm{~h}$ at room temperature, the membrane was incubated overnight at $4{ }^{\circ} \mathrm{C}$ with 1:1000 dilution of anti-TIPE2 antibody (Abcam Cambridge, UK) and anti- $\beta$-actin antibody (ZSJQB Co., Ltd. Beijing, China), then was washed three times and

Table 1 The characteristics of missed abortion patients and healthy controls

\begin{tabular}{llll}
\hline Characteristics & $\begin{array}{l}\text { Missed abortion } \\
\text { patients }\end{array}$ & Healthy controls & $P$ value \\
\hline $\mathrm{N}$ & 36 & 36 & \\
Maternal age, years & $31.56 \pm 0.9546$ & $29.00 \pm 1.522$ & $>0.05$ \\
Gestational age, days & $48.35 \pm 1.492$ & $47.11 \pm 1.80$ & $>0.05$ \\
Gravidity, orders & $2.094 \pm 0.217$ & $1.926 \pm 0.337$ & $>0.05$ \\
\hline
\end{tabular}


incubated with 1:2000 dilution of secondary antibody (goat anti-rabbit IgG) for $1 \mathrm{~h}$ at room temperature. After washing, the membrane was visualized by ECL western blotting detection system (Amersham Biosciences, Little Chalfont, UK). $\beta$-actin was used as the loading control.

\section{Immunohistochemistry}

The decidua and chorion were fixed in $4 \%$ formaldehyde and embedded in paraffin. Five $\mu \mathrm{m}$-thick tissue sections were deparaffinized and rehydrated through decreasing concentrations (from $100 \%$ to $75 \%$ ) of graded ethanol. Then, the specimens were treated with antigen microwave retrieval and endogenous peroxidase blocking and then blocked by $10 \%$ goat serum for $15 \mathrm{~min}$ at $37{ }^{\circ} \mathrm{C}$. Rabbit monoclonal antibody for TIPE2 (1:60 dilution, Abcam, Cambridge, UK) was added to the sections separately overnight at $4{ }^{\circ} \mathrm{C}$ in a wet chamber. For negative controls, primary antibody was replaced by PBS. Then, the slides were incubated with a HRP-conjugated goat anti-rabbit IgG, followed dyaminobenzidine (DAB) staining using HistostainTM-Plus Kit (Gene Tech, Shanghai, China). Cytoplasmic staining of a brown-yellow granulation was considered indicative of positive results. Negative cells had clear cell structure without brown granulation in their cellular cytoplasm. High-resolution images of the stained sections were acquired using an Olympus DP72 digital camera and DP controller software (Olympus, Tokyo, Japan).

The staining intensity and positive expression area were evaluated in a blinded fashion by two independent pathologists. The staining intensity was divided into four grades: - (score 0$),+$ (score 1$),++$ (score 2$)$, and +++ (score 3 ). The positive expression area was also classified into four categories: $-(<1 \%$, score 0$),+(1-33 \%$, score 1$),++(34-$ $66 \%$, score 2$)$, and $+++(67-100 \%$, score 3$)$. The sum of intensity and percentage scores was used as the final TIPE2 staining score. The expression of TIPE2 was defined as follows: no expression (total score 0); weak expression (total score 1 and 2); moderate expression (total score 3 and 4); strong expression (total score 5 and 6).

\section{Measurement of serum TNF- $a$, IL-10, estradiol and progesterone levels}

The blood samples were obtained before vacuum aspiration. The samples were put at $4{ }^{\circ} \mathrm{C}$ for blood clotting and the serum was acquired after centrifugation at $3000 \mathrm{rpm}$ for $15 \mathrm{~min}$ at $4{ }^{\circ} \mathrm{C}$. Then the serum was collected and frozen at $-80{ }^{\circ} \mathrm{C}$ for TNF-a, IL-10, estradiol and progesterone analysis. The levels of serum TNF-a and IL-10 were measured with BD Cytometric Bead Array HUMAN Inflammation Kit (Becton, Dickinson and Company, USA) in accordance with the manufacturer's instruction. Serum estradiol and progesterone levels were measured using Radioimmunoassay (RIA) (lodine (125 l)-Prog RIA Kit and lodine (125 l)-E2 RIA Kit) (JinDing, TianJin, China) on the Gamma Radioimmunoassay Counter.

\section{Statistical analysis}

Data were presented as mean \pm SEM. Differences between groups were analyzed by Unpaired Student's t-test or chi-squared tests. Correlations were studied by Pearson's correlation test. $p<0.05$ was considered statistically significant. GraphPad Prism 5 software (La Jolla, CA, USA) was used to perform data analysis.

\section{Results}

The expression of TIPE2 mRNA in the decidua and chorion of missed abortion patients and healthy controls detected by real-time PCR

Quantitative real-time PCR analysis was performed to detect the TIPE2 mRNA expression in the decidua and chorion of missed abortion patients and healthy controls. However, no significant differences in TIPE2 mRNA expression were observed in both decidua and chorion between the two groups $(p>0.05)$ (Fig. 1a and b).
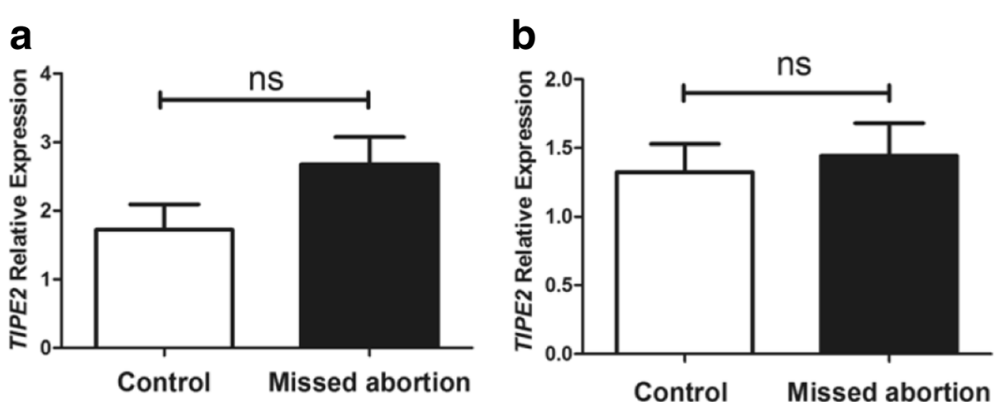

Fig. 1 The expression of TIPE2 mRNA in the decidua and chorion of 36 missed abortion patients and 36 healthy controls detected by quantitative real-time PCR. a The expression of TIPE2 mRNA had no significant differences in decidual tissues between missed abortion patients and normal controls $(p>0.05)$; b No significant differences in TIPE2 mRNA expression were observed in chorionic tissues between the two groups $(p>0.05)$ 
The expression of TIPE2 protein in the decidua and chorion of missed abortion patients and healthy controls detected by western blot

To investigate the expression status of TIPE2 proteins, we detected the protein levels of TIPE2 using western blot analysis in the decidua and chorion of missed abortion patients and healthy controls. The results revealed that the expression of TIPE2 protein in decidual tissues was significantly lower in missed abortion patients than that in healthy controls $(P<0.01)$ (Fig. $2 \mathrm{a}$ and c). However, no significant differences in the expression of TIPE2 protein were found in chorionic tissues between missed abortion patients and healthy controls $(P>0.05)$ (Fig. 2b and d). These data suggested the downregulation of TIPE2 expression in decidual tissues of missed abortion patients.

The expression of TIPE2 protein in the decidua and chorion of missed abortion patients and healthy controls detected by IHC

To further determine the expression sites and levels of TIPE2 proteins, we detected the TIPE2 proteins in the decidua and chorion of missed abortion patients and healthy controls by IHC. The results showed TIPE2 protein expressed in both decidua and chorion of missed abortion and control groups, TIPE2 positive staining localized in the cytoplasm of cytotrophoblasts and syncytiotrophoblasts, villous stromal cells, vessel endothelial cells of chorionic tissues, and decidual glandular epithelial cells, vessel endothelial cells and stromal cells of decidual tissues. By statistical analysis, we found that TIPE2 positive staining was significantly lower in decidual tissues of missed abortion patients than that in healthy control $(p<0.01$; Fig. 3a-c). However, no significant differences in TIPE2 expression were found in chorionic tissues between missed abortion patients and healthy control $(P>0.05$; Fig. $3 \mathrm{~d}-\mathrm{f})$. These results further confirmed that TIPE2 expression was downregulated in decidual tissues of missed abortion patients.

\section{Serum cytokine and hormone levels in missed abortion patients and healthy controls}

We next investigated the levels of Th1-type cytokine TNF-a and Th2-type cytokine IL-10 in the serum of missed abortion patients and healthy subjects. The patients with missed abortion had significantly higher levels of serum TNF-a $(p<0.05$; Fig. 4a), and lower levels of serum IL-10 ( $p<0.05$; Fig. 4b) compared with healthy controls. In addition, serum estradiol and progesterone of gestation time (7-10 weeks) from the two groups were measured respectively by radioimmunoassay previously described. The results showed the levels of serum total estradiol $(p<0.001$; Fig. $4 \mathrm{c})$ and progesterone $(p<0.001$; Fig. $4 d)$ were significantly lower in missed abortion patients than those in healthy controls. These results indicated the important roles of increased Th1-type cytokines, reduced Th2-type cytokines, estradiol and progesterone in missed abortion.

\section{Correlation analysis of TIPE2 protein expression with serum TNF-a, IL-10, estradiol and progesterone levels in missed abortion patients}

To further determine the clinical significance of TIPE2 expression in missed abortion, we accordingly analyzed the correlations of TIPE2 protein expression with IL-10, TNFa, estradiol and progesterone. As shown in Fig. 5a, the expression level of TIPE2 protein was positively correlated with the serum level of IL-10 $(r=0.2631, p=0.0146)$. However, we observed that the expression of TIPE2 had no significant relation to serum TNF-a levels $(r=-0.1469$,
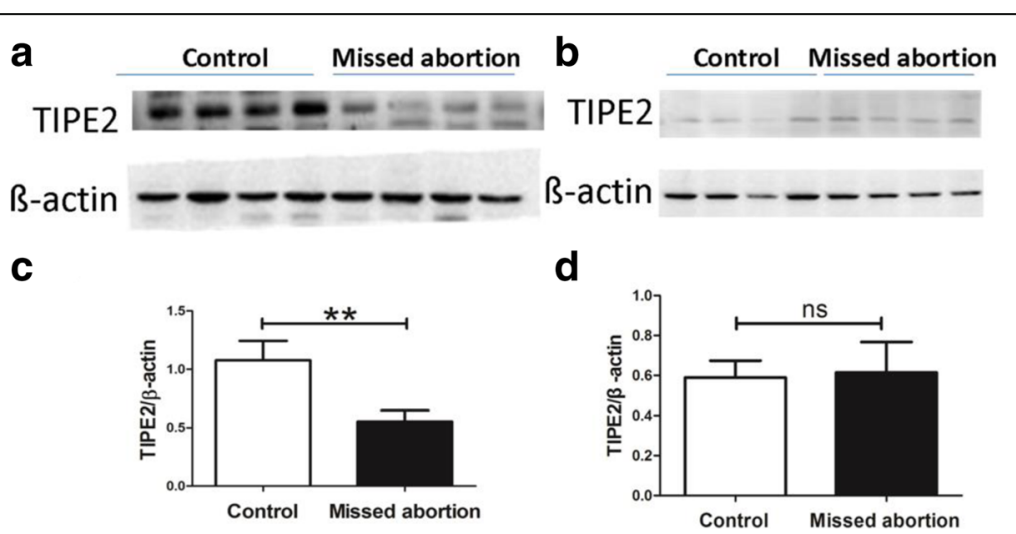

d

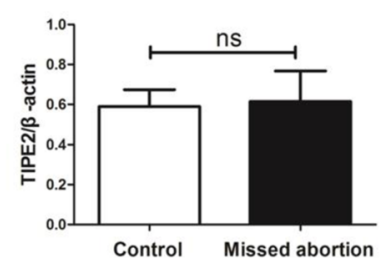

Fig. 2 The expression of TIPE2 protein in the decidua and chorion of 36 missed abortion patients and 36 healthy controls detected by western blot. a The expression of TIPE2 protein in decidual tissues of missed abortion patients and healthy controls; $\mathbf{b}$ The expression of TIPE2 protein in chorionic tissues of missed abortion patients and healthy controls; c The expression of TIPE2 protein in the decidual tissues was significantly lower in missed abortion patients than that in healthy controls $(p<0.01)$; d No significant differences in the expression of TIPE2 protein were found in chorionic tissues between missed abortion patients and healthy controls $(p>0.05)$ 

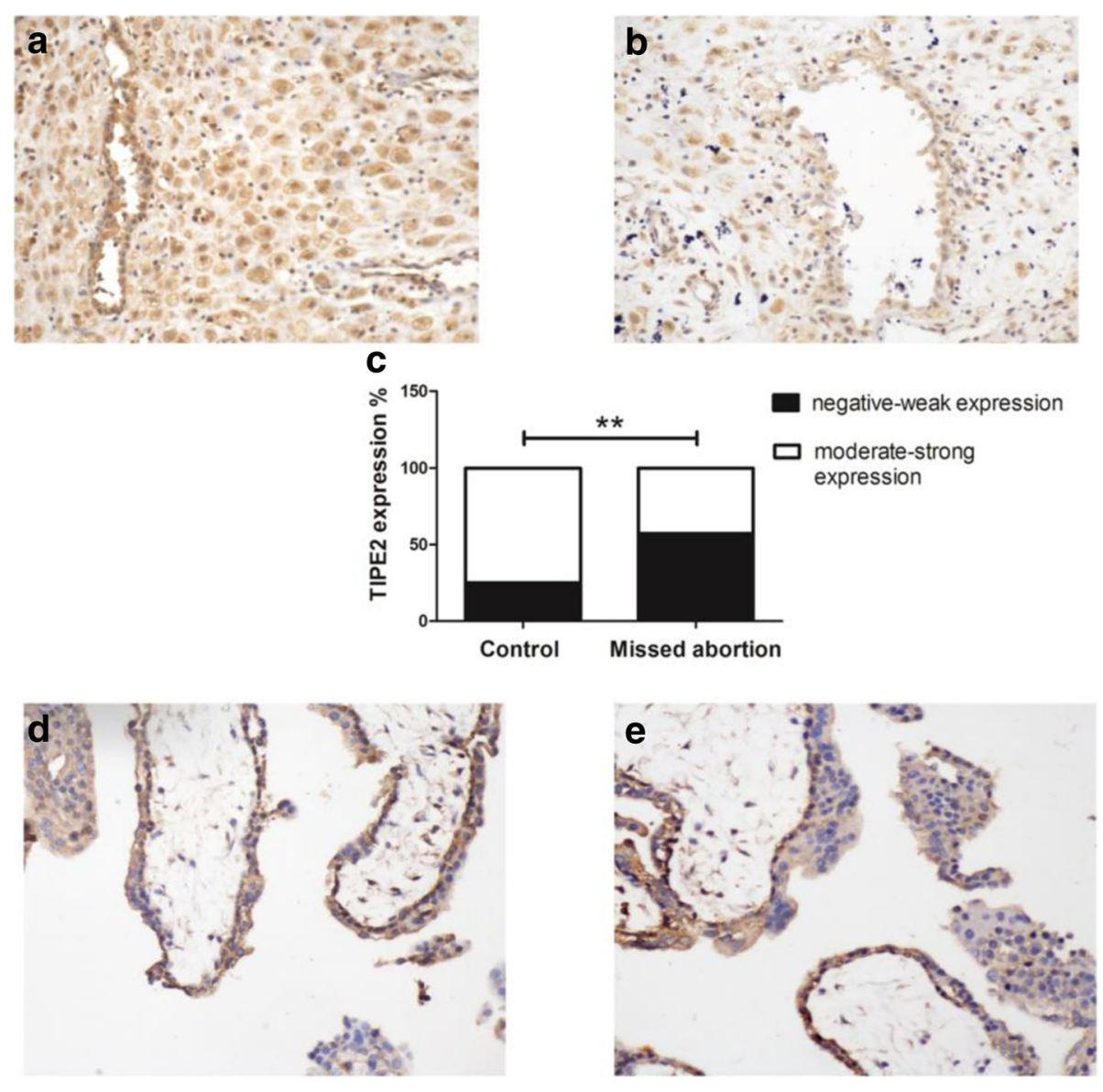

f

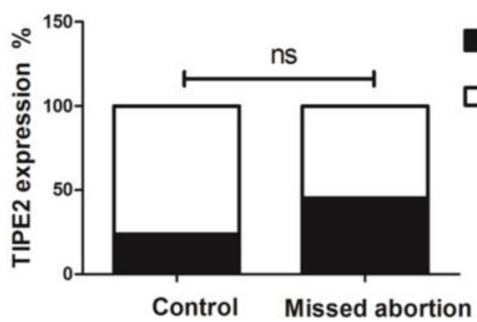

Fig. 3 The expression of TIPE2 protein in the decidua and chorion of 36 missed abortion patients and 36 healthy controls detected by IHC. a The expression of TIPE2 protein in decidual tissues of missed abortion patients (original magnification, $\times 200$ ); $\mathbf{b}$ The expression of TIPE2 protein in decidual tissues of healthy controls (original magnification, $\times 200$ ); c TIPE2 positive staining was significantly lower in decidual tissues of missed abortion patients than that in healthy controls $(p<0.01)$; $\mathbf{d}$ The expression of TIPE2 protein in chorionic tissues of missed abortion patients (original magnification, $\times 200$ ); e The expression of TIPE2 protein in chorionic tissues of healthy controls (original magnification, $\times 200$ ); $\mathbf{f}$ No significant differences in TIPE2 expression were found in chorionic tissues between missed abortion patients and healthy controls $(p>0.05)$

$p=0.6163$ ) (Fig. 5b). Furthermore, there were no statistically significant correlations between TIPE2 protein expression and serum estradiol $(r=-0.2674, p=0.2544)$ and progesterone levels ( $r=-0.2361, p=0.3163)$ (Fig. 5c and d).

\section{Discussion}

Missed abortion is one of the most common complications of pregnancy, several reasons have been identified for the failure of these pregnancies. Among them, immunologically mediated abortion has been paid much attention increasingly. It has been known that an immune suppressed state in maternal-fetal interface is necessary for the mother to tolerate the semi-allograft fetus, and the immunological mechanism occurring in maternal-fetal interface is very complex [27]. TIPE2, a newly identified immune inhibitor, manifests a negative regulatory effect in inflammation and the maintenance of immune homeostasis $[1,2,8]$. At present, abnormal 

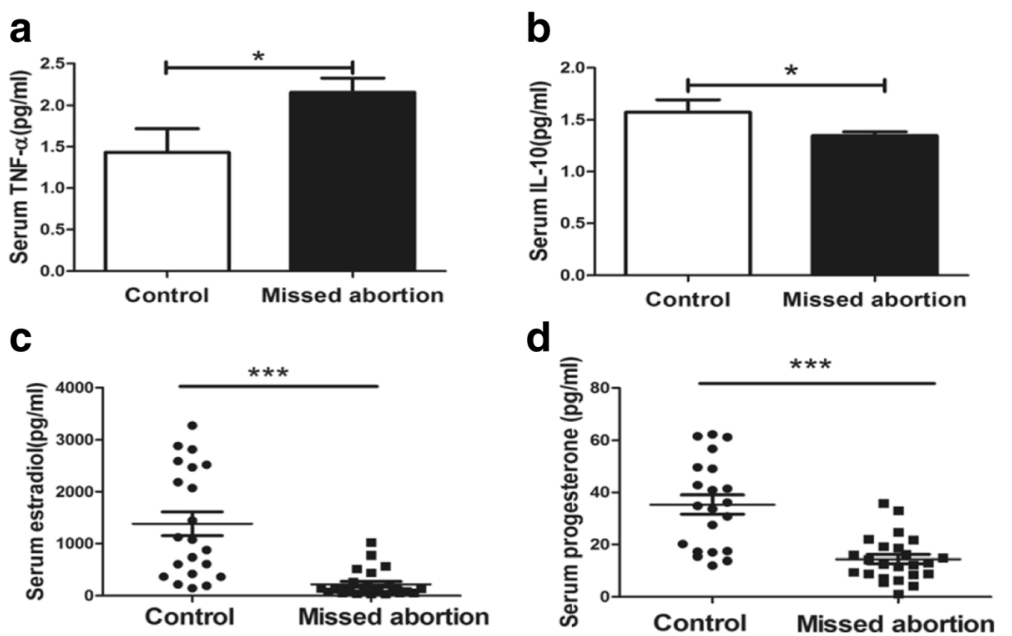

Fig. 4 Serum cytokine and hormone levels in missed abortion patients and healthy controls. a Serum TNF-a level in patients with missed abortion was obviously higher than that in healthy subjects $(p<0.05)$; b Serum IL-10 level was significantly lower in missed abortion patients than that in normal controls $(p<0.05)$; c Serum total estradiol level in missed abortion patients was significantly lower than that in healthy controls $(p<0.001)$; d Serum progesterone level was significantly decreased in missed abortion patients compared with healthy subjects $(p<0.001)$

expression of TIPE2 mRNA and/or protein has been found in several chronic inflammatory diseases and cancers. On one hand, TIPE2 expression is down-regulated in peripheral blood mononuclear cells (PBMCs) of patients with SLE [11] and HBV [9] or HCV-induced hepatitis [12], as well as gastric cancer [13], hepatocellular carcinoma [14] and non-small cell lung cancer tissues [15]. On the other hand, it has been reported that TIPE2 expression is up-regulated in glomeruli from streptozotocin (STZ)-induced diabetic rats and renal biopsies of patients with diabetes [8], and PBMCs of chronic rejection patients [28], as well as renal cell carcinoma tissues

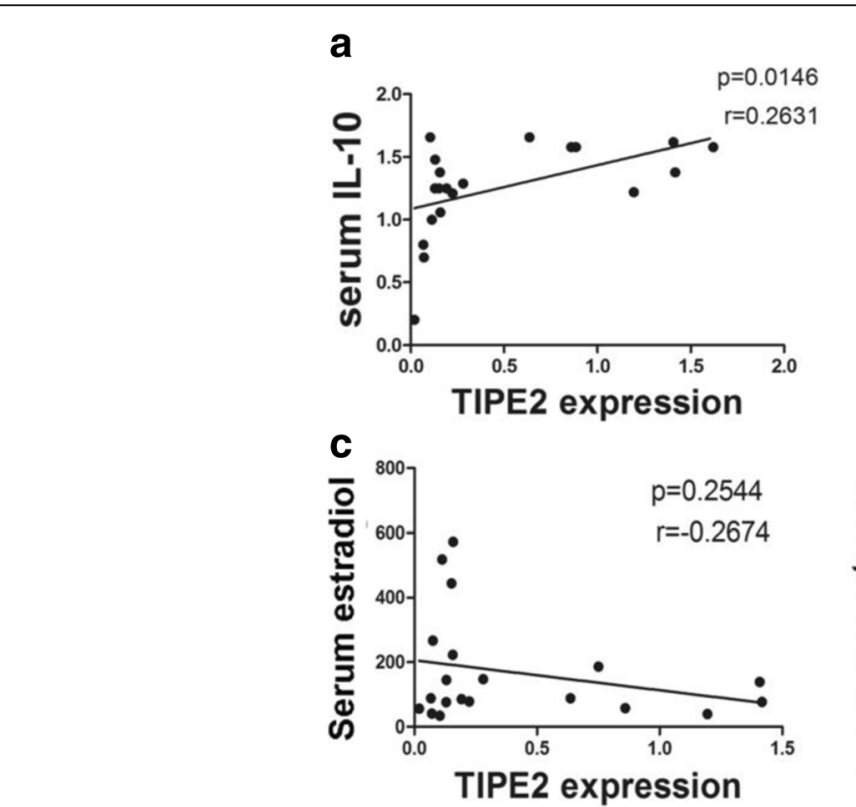

b
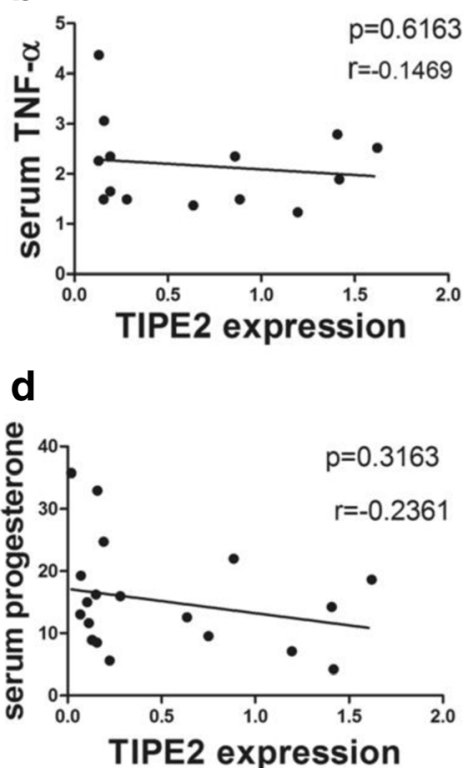

Fig. 5 Correlation analysis of TIPE2 protein expression with serum TNF-a, IL-10, estradiol and progesterone levels in missed abortion patients. a There was a significantly positive correlation between TIPE2 protein expression and serum IL-10 levels $(r=0.2631, p=0.0146)$; b No statistically significant correlation was found between TIPE2 protein expression and serum TNF-a levels $(r=-0.1469, p=0.6163)$; c The expression of TIPE2 had no significant relation to serum estradiol levels $(r=-0.2674, p=0.2544)$; $\mathbf{d}$ There was no statistically significant correlation between TIPE2 protein expression and serum progesterone levels $(r=-0.2361, p=0.3163)$ 
[29], Non-Hodgkin's Lymphoma [30]. Our previous study showed TIPE2 mRNA and protein were both down-regulated in PBMCs of patients with childhood asthma [31]. These results suggest that TIPE2 may involve in the pathogenesis of some chronic inflammatory diseases and cancers, but the mechanism may be different. However, up to now, no reports have been made regarding the role of TIPE2 in missed abortion.

In the present study, we firstly collected the decidual and chorionic tissues of missed abortion patients and healthy controls, and detected the expression of TIPE2 mRNA and protein in these tissues. TIPE2 mRNA expression had no significant differences in the decidual and chorionic tissues between missed abortion patients and healthy controls. The results from western blot demonstrated that TIPE2 protein was down-regulated in the decidual tissues of missed abortion patients compared with healthy controls, while no significant difference in TIPE2 protein was observed in chorionic tissues between missed abortion patients and healthy controls. It has been reported that down-regulation of TIPE2 occurred at the protein but not at mRNA level, because RT-PCR revealed no significant difference in TIPE2 mRNA between hepatocellular carcinoma and its adjacent tissues [25]. The reason for that may be the posttranscription modulation of TIPE2 expression.

Zhang $\mathrm{L}$ et al. reported that TIPE2 protein highly expressed in various types of cells, such as gland epithelial cells in colon and appendix, stratified squamous epithelium in esophagus and cervix [6]. To further investigate the expression sites and protein levels of TIPE2 in maternal-fetal interface, we measured the expression of TIPE2 in the decidual and chorionic tissues of missed abortion patients and healthy controls by IHC. We found that TIPE2 positive staining mainly exists in the cytoplasm of decidual glandular epithelial cells, vessel endothelial cells and stromal cells of decidual tissues. Cytotrophoblasts and syncytiotrophoblasts, villous stromal cells, vessel endothelial cells of chorionic tissues also express low levels of TIPE2 protein. The statistic results confirmed that TIPE2 protein was only reduced in the decidual tissues of missed abortion patients compared with healthy controls. The above data indicate TIPE2 could play important roles in maintaining the maternal-fetal tolerance and decreased TIPE2 expression in the decidua may be related to the development of missed abortion.

Cytokines form a complex regulatory network which maintains homeostasis between the fetus and maternal immune system. It has been reported that Th2-type cytokine IL-10 may play an important role in maternal tolerance of the fetus [32] and increases systemically in patients with a normal pregnancy compared with those with miscarriage. However, Th1-type cytokines, such as TNF- $\alpha$ and IFN- $\gamma$ involved in triggering immunological pregnancy loss, i.e., death of embryos [33, 34]. The TNF$\alpha$ level is markedly elevated in the serum of women with recurrent spontaneous miscarriage. Our results also showed higher serum TNF-a and lower IL-10 levels in missed abortion patients compared with healthy controls. We further analyzed the correlations of TIPE2 with TNF-a and IL-10, and found a positive correlation between TIPE2 protein and IL-10. However, no statistically significant correlation was observed between TIPE2 protein and TNF-a. These results indicate increased Th1-type immune response in patients with missed abortion.

TIPE2 could inhibit inflammatory cells activation by down-regulating pro-inflammatory cytokines and cell mitosis, and the deletion of TIPE2 in mouse results in fatal inflammation and high serum levels of proinflammatory cytokines such as interleukin (IL)-1, IL-6, IL-12 and TNF- $\alpha$. However, the inhibitory cytokine IL10 is also increased in the serum of TIPE2-knockout mice [1]. This is inconsistent with our result that there is a positive correlation between TIPE2 protein and IL10. We speculate that the increased inhibitory cytokine IL-10 may be the results of feedback, while increased IL10 could not enough to inhibit the effect of proinflammatory cytokines in TIPE2-knockout mice. Besides Th1/Th2 cells, the cytokines secreted by Th17/ Treg cells also play important roles in recurrent pregnancy loss [35]. The correlations of TIPE2 with Th17/ Treg cells needs to be further explored in the future.

M2 polarization is important for early successful pregnancies in humans [36]. It has been reported that TIPE2 could promote M2 macrophage differentiation through the activation of PI3K-AKT signaling pathway [37]. Therefore, TIPE2 could play important roles in supporting pregnancy by promoting M2 macrophage differentiation. In addition, trophoblast cell invasion into the maternal endometrium plays a crucial role during human embryo implantation and placentation [38]. However, some reports showed TIPE2 could inhibit the invasion of various cancer cells, including prostate cancer [39] and lung cancer cells [40]. Trophoblast cell invasion possesses limitation, and it is different from tumor cell invasion [41]. The exact effect of TIPE2 on trophoblast invasion remains to be clarified.

Hormonal levels in early pregnancy may have predictive value in regard to outcome of pregnancy. Aksoy S et al. reported that estradiol and progesterone levels in patients with missed abortion or anembryonic pregnancies were significantly lower than those in the normal group [42]. Moreover, it has been known that the major reproductive hormones, such as estradiol and progesterone, are critical modulators of immune reactions during pregnancy and in particular have a key role in inducing peripheral tolerance [43]. Here, we also found that the levels of estradiol and 
progesterone were significantly lower in missed abortion group compared with healthy controls. We further analyzed the associations of TIPE2 protein with estradiol and progesterone levels. However, there were no statistically significant correlations of TIPE2 protein expression with serum estradiol and progesterone levels.

\section{Conclusions}

In conclusion, we demonstrated, for the first time, that TIPE2 protein was down-regulated in decidual tissues of patients with missed abortion, and positively related to the serum IL-10 levels. These data suggest that TIPE2 may be involved in maintaining the maternal-fetal tolerance. Understanding the exact mechanism will hopefully identify more new and effective strategies to diagnose and treat the patients with missed abortion.

\section{Abbreviations}

IHC: Immunohistochemistry; IL: Interleukin; PBMC: Peripheral blood mononuclear cell; qRT-PCR: Quantitative real-time PCR; TIPE2: TNF-a-induced protein 8-like 2 (TNFAIP8L2); TNF-a: Tumor necrosis factor-a

\section{Acknowledgments}

The authors wish to thank the help from all patients enrolled in Department of Gynecology and Obstetrics, Jinan Central Hospital affiliated to Shandong University.

\section{Funding}

The study was funded by National Natural Science Foundation of China $(81,471,437,31,470,856)$, Natural Science Foundation of Shandong (ZR2012HM091, ZR2013HM105), Science and Technology Development Plan provided by Health and Family Planning Committee in Shandong (2014-25).

\section{Availability of data and materials}

Please contact with author for data requests.

\section{Authors' contributions}

Dr. ZTW designed the project and conducted the experimental study. YSS collected the samples, performed the experiments and wrote the manuscript. XYW participated in designing the experiments, writing and reviewing the manuscript. $Y L$ was involved in performing some experiments. HS, LW and XSW were involved in data collection and statistical analysis. LNZ and ZHF were involved in reviewing the manuscript. All authors read and approved the final manuscript.

\section{Ethics approval and consent to participate}

All the subjects included in the study signed informed consents. The study was approved by the Ethics Committee of the Medical Faculty, Shandong University.

\section{Consent for publication}

Not applicable.

\section{Competing interests}

The authors declare that they have no competing interests.

\section{Publisher's Note}

Springer Nature remains neutral with regard to jurisdictional claims in published maps and institutional affiliations.

\section{Author details}

'Department of Gynecology and Obstetrics, Clinical Medical School, Shandong University, 44\# Wenhua Xi Road, Jinan, Shandong 250012, People's Republic of China. ${ }^{2}$ Department of Immunology, School of Basic Medical Sciences, Shandong University, 44\# Wenhua Xi Road, Jinan, Shandong, People's Republic of China. ${ }^{3}$ Department of Clinical Laboratory Services, Linyi People's Hospital, Linyi, Shandong, People's Republic of China.
${ }^{4}$ Department of Gynecology and Obstetrics, Jinan Central Hospital affiliated to Shandong University, 105\# Jiefang Road, Jinan, Shandong 250013, People's Republic of China.

Received: 28 March 2017 Accepted: 29 June 2017

Published online: 29 August 2017

\section{References}

1. Sun $\mathrm{H}$, et al. TIPE2, a negative regulator of innate and adaptive immunity that maintains immune homeostasis. Cell. 2008;133(3):415-26.

2. Zhang $X$, et al. Crystal structure of TIPE2 provides insights into immune homeostasis. Nat Struct Mol Biol. 2009;16(1):89-90.

3. Wang $Z$, et al. TIPE2 protein serves as a negative regulator of phagocytosis and oxidative burst during infection. Proc Natl Acad Sci U S A. 2012;109(38):15413-8.

4. Gus-Brautbar Y, et al. The anti-inflammatory TIPE2 is an inhibitor of the oncogenic Ras. Mol Cell. 2012;45(5):610-8.

5. Carmody RJ, et al. Genomic scale profiling of autoimmune inflammation in the central nervous system: the nervous response to inflammation. J Neuroimmunol. 2002;133(1-2):95-107.

6. Zhang $L$, et al. The unique expression profile of human TIPE2 suggests new functions beyond its role in immune regulation. Mol Immunol. 2011;48(9-10):1209-15.

7. Zhang G, et al. TIPE2 deficiency accelerates neointima formation by downregulating smooth muscle cell differentiation. Cell Cycle. 2013;12(3):501-10.

8. Zhang S, et al. Expression and regulation of a novel identified TNFAIP8 family is associated with diabetic nephropathy. Biochim Biophys Acta. 2010; 1802(11):1078-86.

9. Xi W, et al. Roles of TIPE2 in hepatitis B virus-induced hepatic inflammation in humans and mice. Mol Immunol. 2011;48(9-10):1203-8.

10. Zhang $Y$, et al. TIPE2, a novel regulator of immunity, protects against experimental stroke. J Biol Chem. 2012;287(39):32546-55.

11. Li D, et al. Down-regulation of TIPE2 mRNA expression in peripheral blood mononuclear cells from patients with systemic lupus erythematosus. Clin Immunol. 2009;133(3):422-7.

12. Kong $L$, et al. Downregulation of TIPE2 mRNA expression in peripheral blood mononuclear cells from patients with chronic hepatitis C. Hepatol Int. 2013;7(3):844-9.

13. Zhao Q, et al. Tumor necrosis factor-alpha-induced protein-8 like-2 (TIPE2) upregulates p27 to decrease gastic cancer cell proliferation. J Cell Biochem. 2015:116(6):1121-9.

14. Cao X, et al. Human tumor necrosis factor (TNF)-alpha-induced protein 8-like 2 suppresses hepatocellular carcinoma metastasis through inhibiting Rac1. Mol Cancer. 2013;12(1):149.

15. Li Y, et al. Downregulated TIPE2 is associated with poor prognosis and promotes cell proliferation in non-small cell lung cancer. Biochem Biophys Res Commun. 2015;457(1):43-9.

16. A Comparative Study to Evaluate the Efficacy of Vaginal vs Oral Prostaglandin E1 Analogue (Misoprostol) in Management of First Trimester Missed Abortion. J Clin Diagn Res. 2016.10(5):QC14-8.

17. Clifford K, et al. An informative protocol for the investigation of recurrent miscarriage: preliminary experience of 500 consecutive cases. Hum Reprod. 1994;9(7):1328-32

18. Hatasaka HH. Recurrent miscarriage: epidemiologic factors, definitions, and incidence. Clin Obstet Gynecol. 1994;37(3):625-34.

19. Bulletti C, Flamigni C, Giacomucci E. Reproductive failure due to spontaneous abortion and recurrent miscarriage. Hum Reprod Update. 1996;2(2):118-36.

20. Stray-Pedersen B, Stray-Pedersen S. Etiologic factors and subsequent reproductive performance in 195 couples with a prior history of habitual abortion. Am J Obstet Gynecol. 1984;148(2):140-6.

21. Nakashima A, et al. The balance of the immune system between $T$ cells and NK cells in miscarriage. Am J Reprod Immunol. 2012;67(4):304-10.

22. Wilczynski JR. Immunological analogy between allograft rejection, recurrent abortion and pre-eclampsia - the same basic mechanism? Hum Immunol. 2006;67(7):492-511.

23. Warning JC, McCracken SA, Morris JM. A balancing act: mechanisms by which the fetus avoids rejection by the maternal immune system. Reproduction. 2011;141(6):715-24.

24. Dealtry GB, O'Farrell MK, Fernandez N. The Th2 cytokine environment of the placenta. Int Arch Allergy Immunol. 2000;123(2):107-19. 
25. Clark DA, Arck PC, Chaouat G. Why did your mother reject you? Immunogenetic determinants of the response to environmental selective pressure expressed at the uterine level. Am J Reprod Immunol. 1999;41 (1):5-22.

26. Mellor AL, Munn DH. Immunology at the maternal-fetal interface: lessons for T cell tolerance and suppression. Annu Rev Immunol. 2000;18:367-91.

27. Petroff MG. Immune interactions at the maternal-fetal interface. J Reprod Immunol. 2005;68(1-2):1-13.

28. Jia $L$, et al. TIPE2, a novel biomarker for clinical chronic kidney allograft rejection. Artif Organs. 2013;37(2):221-5.

29. Zhang Z, et al. TIPE2 mRNA overexpression correlates with TNM staging in renal cell carcinoma tissues. Oncol Lett. 2013;6(2):571-5.

30. Hao C, et al. Clinical significance of TIPE2 protein upregulation in nonHodgkin's lymphoma. J Histochem Cytochem. 2016;64(9):556-64.

31. Ma Y, et al. The expression and significance of TIPE2 in peripheral blood mononuclear cells from asthmatic children. Scand J Immunol. 2013;78(6):523-8.

32. Plevyak $\mathrm{M}$, et al. Deficiency of decidual IL-10 in first trimester missed abortion: a lack of correlation with the decidual immune cell profile. Am J Reprod Immunol. 2002;47(4):242-50.

33. Toder $\mathrm{V}$, et al. TNF-alpha in pregnancy loss and embryo maldevelopment: a mediator of detrimental stimuli or a protector of the fetoplacental unit? J Assist Reprod Genet. 2003;20(2):73-81.

34. Yu XW, et al. Tumor necrosis factor receptor 1 expression and early spontaneous abortion. Int J Gynaecol Obstet. 2005;88(1):44-8.

35. Saini V, et al. Cytokines in recurrent pregnancy loss. Clin Chim Acta. 2011;412(9-10):702-8.

36. Tsao FY, et al. M1 macrophages decrease in the deciduae from normal pregnancies but not from spontaneous abortions or unexplained recurrent spontaneous abortions. J Formos Med Assoc. 2017(16)30270-4.

37. Liu R, et al. Negative Immune Regulator TIPE2 Promotes M2 Macrophage Differentiation through the Activation of PI3K-AKT Signaling Pathway. PLoS One. 2017;12(1):e0170666.

38. Nissi R, et al. Circulating matrix metalloproteinase MMP-9 and MMP-2/TIMP2 complex are associated with spontaneous early pregnancy failure. Reprod Biol Endocrinol. 2013;11:2.

39. Lu Q, et al. TIPE2 Overexpression Suppresses the Proliferation, Migration, and Invasion in Prostate Cancer Cells by Inhibiting PI3K/Akt Signaling Pathway. Oncol Res. 2016;24(5):305-13.

40. Li Z, et al. TIPE2 suppresses angiogenesis and non-small cell lung cancer (NSCLC) invasiveness via inhibiting Rac1 activation and VEGF expression. Oncotarget. 2016;7(38):62224-9.

41. Von Rango U, et al. Fetal tolerance in human pregnancy -A crucial balance between acceptance and limitation of trophoblast invasion. Immunol Lett. 2008;115(1):21-32.

42. Aksoy S, et al. The prognostic value of serum estradiol, progesterone, testosterone and free testosterone levels in detecting early abortions. Eur J. Obstet Gynecol Reprod Biol. 1996;67(1):5-8.

43. La Rocca C, et al. The immunology of pregnancy: regulatory $T$ cells control maternal immune tolerance toward the fetus. Immunol Lett. 2014;162(1 Pt A):41-8.

\section{Submit your next manuscript to BioMed Central and we will help you at every step:}

- We accept pre-submission inquiries

- Our selector tool helps you to find the most relevant journal

- We provide round the clock customer support

- Convenient online submission

- Thorough peer review

- Inclusion in PubMed and all major indexing services

- Maximum visibility for your research

Submit your manuscript at www.biomedcentral.com/submit

Biomed Central 